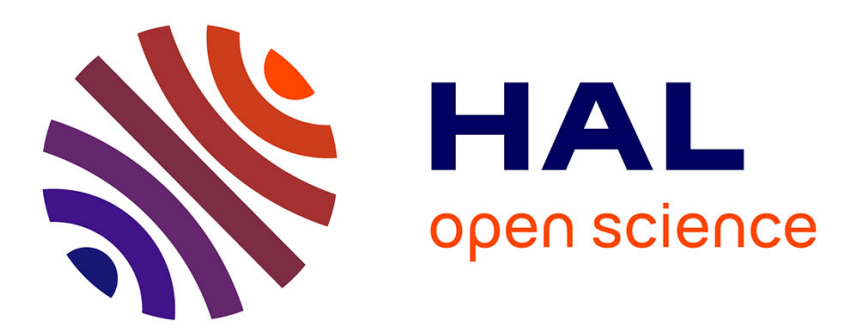

\title{
Random balance designs for the estimation of first order global sensitivity indices
}

Stefano Tarantola, Debora Gatelli, Thierry A. Mara

\section{To cite this version:}

Stefano Tarantola, Debora Gatelli, Thierry A. Mara. Random balance designs for the estimation of first order global sensitivity indices. Reliability Engineering and System Safety, 2006, 91 (6), pp.717727. 10.1016/j.ress.2005.06.003 . hal-01065897

\section{HAL Id: hal-01065897 https://hal.science/hal-01065897}

Submitted on 18 Sep 2014

HAL is a multi-disciplinary open access archive for the deposit and dissemination of scientific research documents, whether they are published or not. The documents may come from teaching and research institutions in France or abroad, or from public or private research centers.
L'archive ouverte pluridisciplinaire HAL, est destinée au dépôt et à la diffusion de documents scientifiques de niveau recherche, publiés ou non, émanant des établissements d'enseignement et de recherche français ou étrangers, des laboratoires publics ou privés. 


\title{
Random Balance Designs for the Estimation
}

\section{of First Order Global Sensitivity Indices}

\author{
S. Tarantola(*), D. Gatelli(*), T. A. Mara(**)
}

(*) Joint Research Centre, European Commission

TP361, Institute of the Protection and Security of the Citizen

\author{
Via E. Fermi 1 \\ 21020 Ispra (VA) ITALY \\ stefano.tarantola@jrc.it \\ Tel. +390332789928 \\ Fax. +390332785733
}

(**) Laboratory of Industrial engineering,

University of Reunion Island, BP 7151, 15 avenue René Cassin,

97715 Saint-Denis, France 


\begin{abstract}
We present two methods for the estimation of main effects in global sensitivity analysis. The methods adopt Satterthwaite's application of random balance designs in regression problems, and extend it to sensitivity analysis of model output for non-linear, non-additive models. Finite as well as infinite ranges for model input factors are allowed. The methods are easier to implement than any other method available for global sensitivity analysis, and reduce significantly the computational cost of the analysis. We test their performance on different test cases, including an international benchmark on safety assessment for nuclear waste disposal originally carried out by OECD/NEA.
\end{abstract}

KEY WORDS: computational models, uncertainty analysis, global sensitivity analysis 


\section{INTRODUCTION}

The paper presents two procedures for the estimation of main effects in sensitivity analysis of model output. The estimation of main effects is the objective of a sensitivity analysis problem setting known as Factors Prioritization (FP) [1]. In this setting, the factor importance is defined as the expected amount by which the variance of the model output is reduced when a given input factor is fixed to its true, albeit unknown, value within its range of uncertainty. The larger the reduction of the output variance due to fixing one factor, the higher the main effect for that factor, and the higher the importance of that factor. In setting FP the factors are fixed one at a time, all the others being averaged over their range of variation. As known to practitioners, this setting is blind to interactions among factors $[1,2,4,5,8,13,15,16]$.

The ideal use of setting FP is for prioritization of research, whereby the factor most deserving of better experimental observation is identified. Setting FP is tackled by estimating main effects, which, in a variance-based context, are expressed as $V_{X_{i}}\left\lfloor E_{X_{-i}}\left(Y \mid X_{i}\right)\right\rfloor / V(Y)$ [1]. Here, Y is the model output, $X_{i}$ is the generic input factor, $E_{X_{-i}}$ is the average that operates upon all the factors but $X_{i}$, and $V_{X_{i}}$ is the variance that operates upon $X_{i}$.

Note that other settings exist for quantitative sensitivity analysis. For example, a very efficient screening experiment exists [2] to identify non-influential factors in large models. This is useful in the context of the setting known as "factors fixing" (FF) [1]. The focus of this paper is on the FP setting, to which we restrain our experiments.

The proposed procedures combine Satterthwaite's random balance designs [3] with the Fourier Amplitude Sensitivity Test (FAST) (see [4] for a review, see [5] for a generalisation). In Section 2 we illustrate the two methods and in Section 3 we test their performance against the best available recipe for global sensitivity analysis, recently appeared in [1]. The tests are carried out on an analytical test function widely used for benchmarking sensitivity analysis procedures. In Section 4, another test is carried out on the Level E model, an international benchmark on safety assessment for nuclear waste disposal originally carried out by OECD/NEA [7], and largely applied in the literature. The tests show the superiority of the proposed procedures. 


\section{THE PROPOSED METHODS}

The classic FAST method [4] is based on selecting N design points over a particular space-filling curve in the $\mathrm{k}$-th dimensional input space, built as to explore each dimension (factor) with a different frequency $\left\{\omega_{1}, \omega_{2}, \ldots, \omega_{k}\right\}$. A quite complex algorithm is used to set the frequencies such that they are free of interferences up to a given order $\mathrm{M}$ (usually $\mathrm{M}=6$ ). The computational model is executed at each design point and the Fourier spectrum is calculated on the model output at specific frequencies $\left\{\omega_{i}, 2 \omega_{i}, \ldots, M \omega_{i}\right\}$ to estimate the sensitivity index of factor $X_{i}$.

The first method proposed here is based on random balance design (RBD). We first select $\mathrm{N}$ design points over a curve in the input space. Contrarily to FAST, we explore the input space using the same frequency $\omega$, to avoid the use of the algorithm cited above. However, due to that, the curve is not space-filling but covers only a sub-set of the whole input space. Therefore, we take random permutations of the coordinates of such points, to generate a set of scrambled points that cover the input space. The model is then evaluated at each design point. Subsequently, the model outputs are re-ordered such that the design points are in increasing order with respect to factor $X_{i}$. The Fourier spectrum is calculated on the model output at the

frequency $\omega$ and at its higher harmonics $\{\omega, 2 \omega, \ldots, M \omega\}$ and yields the estimate of the sensitivity index of factor $X_{i}$. The model outputs are re-ordered with respect to the other factors (and the Fourier spectra are calculated accordingly) to obtain all the other the sensitivity indices.

The second method proposed is HFR, a hybrid version that combines classic FAST and RBD.

The parametric curve used in the classic FAST is defined as:

$$
X_{i}\left(s_{j}\right)=G_{i}\left(\sin \omega_{i} s_{j}\right), \quad \forall i=1,2, \ldots, k ; \quad \forall j=1,2, \ldots, N
$$

where $X_{i}$ is the i-th input factor, $G_{i}$ are functions to be chosen by the analyst to get the desired probability density function for $X_{i}, s$ is the parametric variable varying in $(-\pi ; \pi)$ which is sampled over its range using $\mathrm{N}$ points, and the frequencies $\omega_{i}$ are selected such that they are free of interferences 
up to a given order $\mathrm{M}$ (usually set to 4 or 6 ). For example, eq 1 is selected as $X_{i}(s)=\frac{1}{2}+\frac{1}{\pi} \arcsin \left(\sin \omega_{i} s\right)$ in [5] to get a uniform distribution for $X_{i}$ in $(0 ; 1)$.

The selection of the $\omega_{i}$ is made using an algorithm (see [4]). The FAST sample design implies a lower bound on the sample size, which the theory fixes at $N_{\min }=2 M \max \left\{\omega_{i}\right\}+1$. However, $\max \left\{\omega_{i}\right\}$ is an increasing function of $\mathrm{k}$ and, for large $\mathrm{k}$, the sample size and the related computational cost, can be too high to be acceptable.

In the RBD approach all the factors are sampled using the same frequency $\omega$, which is an arbitrary integer, set to 1 for simplicity. Anyway, $\omega$ could assume any other value up to $(\mathrm{N}-1) / 2 \mathrm{M}$, which is the maximum value that is allowed by the theory: higher values would cause the frequency to exceed the sampling dimension $\mathrm{N}$.

A sample of $\mathrm{N}$ points over $(-\pi ; \pi)$ is generated using the parametric equation:

$X_{i}\left(s_{i j}\right)=G_{i}\left(\sin \omega s_{i j}\right), \quad \forall i=1,2, \ldots, k ; \quad \forall j=1,2, \ldots, N$

where $\left\{s_{i 1}, s_{i 2}, \ldots, s_{i N}\right\}$ denotes the i-th random permutation of the N points. For each factor $X_{i}$ equation (2) provides a different random permutation.

The model is evaluated $\mathrm{N}$ times over the sample of size $\mathrm{N}$.

$Y\left(s_{j}\right)=f\left(X_{1}\left(s_{1 j}\right), X_{2}\left(s_{2 j}\right), \ldots, X_{k}\left(s_{k j}\right)\right) \quad \forall j=1,2, \ldots, N$

The values of model output $Y\left(s_{j}\right), \mathrm{j}=1, . . \mathrm{N}$, are then re-ordered $\left(Y^{R}\left(s_{j}\right)\right)$ such that the corresponding values of $X_{1}\left(s_{1 j}\right)$ are ranked in increasing order. By so doing, the harmonic content of $X_{1}$ propagates through $f$ to $Y^{R}\left(s_{j}\right)$. The sensitivity of $Y$ to $X_{1}$ is determined by the harmonic content of $Y^{R}$, which is quantified by its Fourier spectrum

$$
F(\omega)=\frac{1}{\pi} \sum_{j=1}^{N} Y^{R}\left(s_{j}\right) \exp \left(-\operatorname{Im} k \omega s_{j}\right)
$$

evaluated at $\omega=1$ and its higher harmonics (in our case $\omega=2, \omega=3, \ldots$ ) up to order $\mathrm{M}=6$. 
In the discrete,

$\hat{V}_{1}=\operatorname{Var}\left[E\left(Y \mid X_{1}\right)\right]=\left.\sum_{l=1}^{M} F(\omega)\right|_{w=l}=\sum_{l=1}^{M} F(l)$

provides, in a variance-based context (Saltelli et al., 2004), an estimate of $V_{1}$, i.e. the nominator of the main effect for the first factor. The procedure is then repeated for all the other factors whereby the same set of model output is just re-ordered according to $X_{i}\left(s_{i j}\right)$ and (4) and (5) are used to estimate $V_{i}, \mathrm{i}=2, \ldots, \mathrm{k}$. With the use of permutations, the total cost is kept down to N, instead of $\sim \mathrm{k}^{*} \mathrm{~N}$ (like in Sobol' and FAST). Note that random permutations are also used to generate replicated LHS designs for the estimation of importance measures [8].

The HFR method combines RBD with classic FAST. The $\mathrm{k}$ factors are partitioned in groups of equal cardinality. RBD is applied independently within each group of factors. FAST is applied between the groups: here a different frequency is associated to each group.

To make an example, in a six-factor model we can set-up three groups of two factors each, using frequencies $\omega_{1}=1, \omega_{2}=7, \omega_{3}=11$ and two different random permutations. Each random permutation, being associated with three different frequencies, provides a separate design for each factor.

In alternative, we could set up two groups of three factors each; the procedure is the same and the results are equally satisfactory.

The sampling design of HFR combines the accuracy of classic FAST with the computational cheapness of $\mathrm{RBD}$, as we shall see on a number of test cases.

\section{ANALYTIC TESTS}

\subsection{The function of Sobol'}

The first test function has been proposed by Sobol' and has been widely used as benchmark for sensitivity analysis (see eg., [9]). The function is defined as: 


$$
f=\prod_{i=1}^{k} g_{i}\left(X_{i}\right)
$$

where $k$ is the number of input factors and $g_{i}\left(x_{i}\right)$ is given by

$$
g_{i}\left(x_{i}\right)=\frac{\left|4 X_{i}-2\right|+a_{i}}{1+a_{i}}, \quad \text { for } 0 \leq X_{i} \leq 1 \text { and } a_{i} \geq 0 \text {. }
$$

The parameter $\mathrm{a}_{\mathrm{i}}$ is set to determine the relative importance of the $X_{\mathrm{i}}{ }^{\prime}$ s. For $\mathrm{a}_{\mathrm{i}}=0$ the corresponding factor $X$ is very important, for $a_{i}=1$ it is relatively important, while for $a_{i}=9$ it becomes non important and for $a_{i}=99$ non significant, given that the range of uncertainty of $g_{i}\left(x_{i}\right)$ depends exclusively on the value of $a_{i}$. In a case where all the $a_{i}{ }^{6}$ s are equal, the factors have the same level of importance; this level is in any case quantified by $\mathrm{a}_{\mathrm{i}}$.

The analytical partial variances of the first order $\left(V_{i}\right)$ and the total unconditional variance $(V)$ of the model output can be computed analytically:

$$
V_{i}=\frac{1}{3\left(1+a_{i}\right)^{2}}, \quad V=\prod_{i=1}^{k}\left(V_{i}+1\right)-1,
$$

from which the first order sensitivity index $S_{i}=V_{i} / V$ can be calculated.

In the first test we set the $\mathrm{a}_{\mathrm{i}}$ as $\{0,1,4.5,9,99,99,99,99\}$, so that the first factor is the most important, and the last four factors are the least important. The analytic indices $S_{i}$ and the estimates at N=1,000 and $\mathrm{N}=10,000$ are given in Table 1 . With the RBD approach, all the estimated indices converge towards the analytic values, although the estimates for the least important factors are slightly overestimated. In HFR, we grouped the eight factors into two groups, associated with the frequencies $\omega=11$ and $\omega=35$. The HFR estimates for the least important factors are closer to the analytic values. In summary, RBD yields better estimates for the important factors, whilst HFR better detects the non important factors.

To better investigate the statistical properties of the two approaches, we replicate the procedure $r=50$ times and calculate the average and the standard deviation of the $S_{i}$ over the replicates (see Table 2). The tests are repeated at increasing sample sizes $\mathrm{N}=500, \mathrm{~N}=1,000$ and $\mathrm{N}=2,000$. We note that the HFR seems to perform better, both in terms of average (in 21 cases out of 24) and standard deviation (in 18 cases out of 24). In other words, in HFR the average is better approximating the analytic values, and the standard 
deviation is smaller than in RBD, indicating a smaller dispersion of the 50 estimates around the average value.

\subsection{Performance for large-dimensional models and comparison with the method of Sobol' as extended by Saltelli}

We test the performance of the proposed methods in the case of models with a large number of factors. We consider the function of Sobol' with $\mathrm{k}=100$ factors.

Four factors are very important $\left(\mathrm{a}_{\mathrm{i}}=0\right)$, four other factors are fairly important $\left(\mathrm{a}_{\mathrm{i}}=1\right)$, two other factors are less important $\left(\mathrm{a}_{\mathrm{i}}=9\right)$ and the remaining 90 factors are irrelevant $\left(\mathrm{a}_{\mathrm{i}}=99\right)$.

The analytic values for these four groups of factors are respectively $\{0.09820 .02459 .8173 \mathrm{e}-0049.8173 \mathrm{e}-$ $006\}$.

We test the performance of the RBD approach against the method of Sobol' as extended by Saltelli [6], with $\mathrm{N}=100$ and total computational cost $\mathrm{C}=\mathrm{N}(\mathrm{k}+2)=10,200$. Indeed, with the Sobol' or Saltelli's methods the computational cost depends on the number of factors $(\mathrm{k})$, while with the proposed methods the computational cost is equal to the sample size $(\mathrm{C}=\mathrm{N})$. Therefore, with a small number of model runs, we can estimate the first order sensitivity indices for models with a very large number of factors.

Figure 1 displays the results of this test case. The method of Sobol' gives better estimates for the less important factors, but this is not interesting in the context of setting FP. The proposed method with $C=2,000$ yields better estimates than the method of Sobol' with $C=10,200$ for the most important factors in terms of setting FP.

\subsection{Performance for large number of important factors and comparison with the classic FAST.}

Before licensing the computational scheme proposed in this paper we believe important to check whether it works also when the number of important factors in the model is very large. In fact, important factors are easier to detect when they are few. As their number rises, the computational method needs to be very accurate to identify them all. We test the performance of the RBD method on a model with a high fraction of important factors. We consider the g-function with 10 very important factors and 10 non significant factors. The result is given in Figure 2 (a). We note that, even at relatively small sample size $(C=N=5,000)$, the important factors can be clearly distinguished from the non significant ones. 
We also test the hybrid version and compare it against the classic FAST. This latter requires a minimum sample size of $\mathrm{N}=8,377$ under the same conditions. In the hybrid version we choose five groups of factors each composed by four factors. Frequencies for the groups have been set at 11, 21, 27, 35, 39 .

Figure 2(a) shows that classic FAST gives better results for non significant factors while it overestimates the important ones. The proposed methods give similar results, yet the hybrid approach has a lower variance and better approximates analytic values (see Table 3). Note that the variance of the estimates for the important and the non important factors has been obtained across each set of 10 factors, and not by replicating the experiments.

We also try an extreme case considering a model with 20 factors, 15 of each are very important (Figure 2 (b)). The proposed methods can detect the important factors from the non significant ones at $\mathrm{C}=\mathrm{N}=10,000$. Again, the classic FAST performs better for non significant factors, while the important factors are overestimated. The HFR version, implemented in the same way as in the previous case, provides the more accurate estimates for important factors with respect to the other two methods. Comparing Figure 2(a) with Figure 2(b), and also Tables 3 and 4, as the number of significant factors increases, the hybrid version becomes the most precise.

\section{APPLICATION: THE LEVEL-E MODEL}

We apply the method to a real test case. The Level E was used both as a benchmark of Monte Carlo computation ([10], [11]) and as a benchmark for sensitivity analysis methods (Level S, [7]). This test case has been extensively used by several authors, see [12] for a review. The model predicts the radiological dose to humans over geological time scales due to the underground migration of radionuclides from a nuclear waste disposal site through a system of natural and engineered barriers.

The model has a total of 33 parameters, 12 of which are taken as independent uncertain parameters (Table 5); the core of the model is a set of partial differential equations which describes the nuclide migration in the geosphere. (See [1] for a complete description of the model).

The model is time dependent: the simulated time frame ranges from $210^{4}$ to $910^{6}$ years. The predictive uncertainty about $Y(t)$ is due to uncertainties in model parameters. 
The probability distributions for the factors have been selected on the basis of expert judgment. For indepth discussion of the model and its predictions, see [7] and [11]).

After generating the sample $(\mathrm{N}=4,000)$ and running the Level-E model, we used the output to calculate, with the RBD approach, the main effects over the simulated period. Results of the main effects for the two most influential factors (stream flow rate and water travel speed in the first geosphere layer) are given in Figure 3.

Homma and Saltelli [13] showed how the approach proposed by Sobol' [14] to estimate main effects outperforms both crude Monte Carlo sampling and Latin Hypercube sampling. Here we compare our proposed approach against that proposed by Saltelli [6], which is a further improvement with respect to that of Sobol' [14]. We consider a case with N=550 for the method of Saltelli [6].

The RBD approach better approximates the asymptotic values (obtained at very large sample size using the method of Saltelli) than the one implemented by Saltelli himself (Figure 3). Besides, the computational cost of the method of Saltelli is equal to $\mathrm{C}=\mathrm{N}(2 \mathrm{k}+2)=550 * 26=14,300$ while the cost of the proposed methods is only $\mathrm{C}=4,000$.

In Figure 4 we compare the performance of the RBD approach against the hybrid HFR approach for the estimation of the main effects. The hybrid approach is implemented with three groups of (four) factors, to which we assign the frequencies 11, 27 and 39. The hybrid approach is worse for the two most important factors (Figure 4(a) and 4(b)), while both methods perform equally well for the non significant factors (Figure 4(c) and 4(d)).

To give more evidence of the performance of the two methods, we run each of them ten times so that the width of the estimates can be evaluated and compared. In Figure 5 the estimates widths of factors 4 and 12 are shown, for both methods. This HFR approach yields less varying estimates, especially at $\mathrm{t}=100,000 \mathrm{yr}$, as confirmed by the standard deviation calculated across the ten estimates (see Figure 6). The means of the main effects over the 10 experiments for factor 4 show that the hybrid version is less precise than the RBD approach. Instead, for factor 12 , the means of the hybrid approach are closer to the asymptotic values. In summary, it is difficult to establish which method to prefer, as their performance depends on the factor considered and on the time. 


\section{CONCLUSIONS}

Our analysis shows that the two new methods proposed in this paper, that based on random balance designs (RBD) and the hybrid FAST - RBD (HFR), have computational advantages over all other strategies for the estimate of variance-based measures currently employed in the literature.

The two methods are substantially equivalent, as each of them can perform better or worst in different case studies. Of the two proposed methods, the HFR is slightly more complex to implement than RBD, and it is up to the analyst the choice of the frequencies and the selection of the subsets of factors. The persisting drawback is that we can employ these approaches only for setting FP, as the proposed methods only supply estimates for main effects.

\section{ACKNOWLEDGEMENTS}

The authors would like to acknowledge Professor Max Morris (Iowa State University, IA) and Andrea Saltelli (Joint Research Centre, Italy) for their kind support and useful suggestions.

\section{REFERENCES}

[1] Saltelli, A., Tarantola, S., Campolongo, F., Ratto, M., (2004), "Sensitivity Analysis in Practice," Wiley (eds.).

[2] Morris, M.D., (1991), "Factorial Sampling Plans for Preliminary Computational Experiments," Technometrics, 33(2), 161-174.

[3] Satterthwaite, F. E., (1959), “Random Balance Experimentation,” Technometrics, (vol. 1), n.2, May.

[4] Cukier R. I., Levine H. B., and Shuler K. E., (1978), "Nonlinear Sensitivity Analysis of Multiparameter Model Systems," Journal of Comp. Physics 26, 1-42.

[5] Saltelli, A., Tarantola, S., and Chan, K. (1999), “A Quantitative Model-Independent Method for Global Sensitivity Analysis of Model Output," Technometrics, (vol. 41), n.1, February.

[6] Saltelli A., (2002), “Making Best Use of Model Valuations to Compute Sensitivity Indices," Computer Physics Communications, 145:280-297. 
[7] OECD/NEA PSAG User group, PSACOIN Level S intercomparison, eds. Alonso A., Robinson P., Bonano E. J. and Galson D.A. (1993), Nuclear Energy Agency, Organisation for Economic Cooperation and Development, Paris.

[8] McKay, M. D. (1995) Evaluation Prediction Uncertainty, NUREG/CR-6311, LA-12915-MS, Los Alamos National Laboratory.

[9] Saltelli, A., and Sobol', I. M. (1995), “About the Use of Rank Transformation in Sensitivity Analysis Model," Reliability Engineering and System Safety, 50, 225-239.

[10] Robinson, P. C., and Hodgkinson, D. P. (1987), "Exact Solutions for Radionuclide Transport in the Presence of Parameter Uncertainty," Radioactive Waste Manag. Nucl. Fuel Cycle 8(4), 283-311.

[11] OECD/NEA PSAC User group, PSACOIN Level E intercomparison, eds. Goodwin B.W., Laurens J.M., Sinclair J.E., Galson D.A. and Sartori E. (1989), Nuclear Energy Agency, Organisation for Economic Cooperation and Development, Paris.

[12] Saltelli, A., and Tarantola, S. (2002), “On the Relative Importance of Input Factors in Mathematical Models: Safety Assessment for Nuclear Waste Disposal," Journal of American Statistical Association, 97, 702-709.

[13] Homma, T., and Saltelli, A., (1995), "Use of Sobol's Quasirandom Sequence Generator for Integration of Modified Uncertainty Importance Measure," Journal of Nuclear Science and Technology, 32(11) 11641173.

[14] Sobol', I. M. (1993), "Sensitivity Analysis for Nonlinear Mathematical Models," Mathematical Modeling \& Computational Experiment 1, 407-414.

[15]Saltelli, A., Chan, K., Scott, M., (2000) (Eds.), "Sensitivity Analysis, Probability and Statistics Series”, John Wiley.

[16] Iman, R. L. and Shortencarier, M. J., (1984), A FORTRAN 77 program and user's guide for the generation of Latin hypercube and random samples for use with computer models, SANDIA Laboratory report SAND83-2365 


\section{FIGURE CAPTIONS}

Figure 1: First Test Case: G-function. Estimation of First Order Sensitivity Indices using the RBD Approach at 1,000 Runs, at 2,000 Runs and the Method of Sobol' at 20,000 Runs.

Figure 2 (a): First Test Case: G-function. The Estimated Values for the RBD approach, classic FAST and HFR, in a Case Study with a Large Number of Important Factors (10 very important and 10 non significant ones). $\mathrm{N}=5,000$ for the HFR and the RBD approaches, while $\mathrm{N}=8377$ for the Classic FAST.

Figure 2 (b): First Test Case: G-function. The Estimated Values for the RBD approach, classic FAST and HFR, in a Case Study with a Large Number of Important Factors (15 very important and 5 non significant ones), $\mathrm{N}=10,000$.

Figure 3 (a): Second Test Case: Level-E. Comparison between the method of Saltelli (2002) and the RBD approach, for input factor 4 .

Figure 3 (b): Second Test Case: Level-E. Comparison between the method of Saltelli (2002) and the RBD approach, for input factor 12

Figure 4 (a): Second Test Case: Level-E. Comparison between the RBD and the HFR approaches, for input factor 4 .

Figure 4 (b): Second Test Case: Level-E. Comparison between the RBD and the HFR approaches, for input factor 12 .

Figure 4 (c): Second Test Case: Level-E. Comparison between the RBD and the HFR approaches, for input factor 3 .

Figure 4 (d): Second Test Case: Level-E. Comparison between the RBD and the HFR approaches, for input factor 9 .

Figure 5 (a): Second Test Case: Level-E. Estimates widths for 10 experiments (for factor 12 and factor 4), in the RBD approach.

Figure 5 (b): Second Test Case: Level-E. Estimates widths for 10 experiments (for factor 12 and factor 4 ), in the HFR approach.

Figure 6 (a): Comparison between the standard deviation of 10 level-E experiments in the proposed methods (HFR and RBD) for factor 4. 
Figure 6 (b): Comparison between the standard deviation of 10 level-E experiments in the proposed methods (HFR and RBD) for factor 12.

Figure 7 (a): Comparison between the means of 10 level-E experiments in the proposed methods (HFR and $\mathrm{RBD})$ for factor 4.

Figure 7 (b): Comparison between the means of 10 level-E experiments in the proposed methods (HFR and RBD) for factor 12 . 
FIGURES

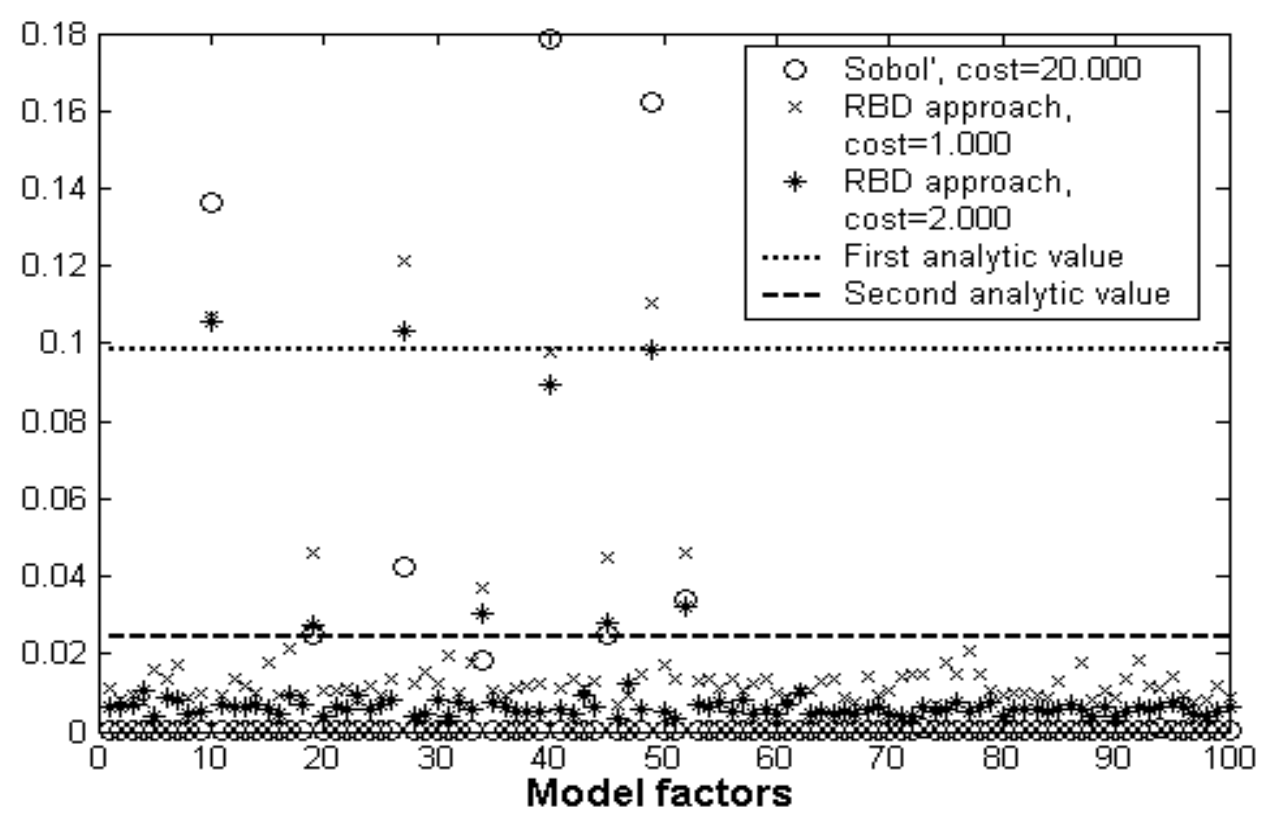

Figure 1: First Test Case: G-function. Estimation of First Order Sensitivity Indices using the RBD Approach at 1,000 Runs, at 2,000 Runs and the Method of Sobol' at 20,000 Runs.

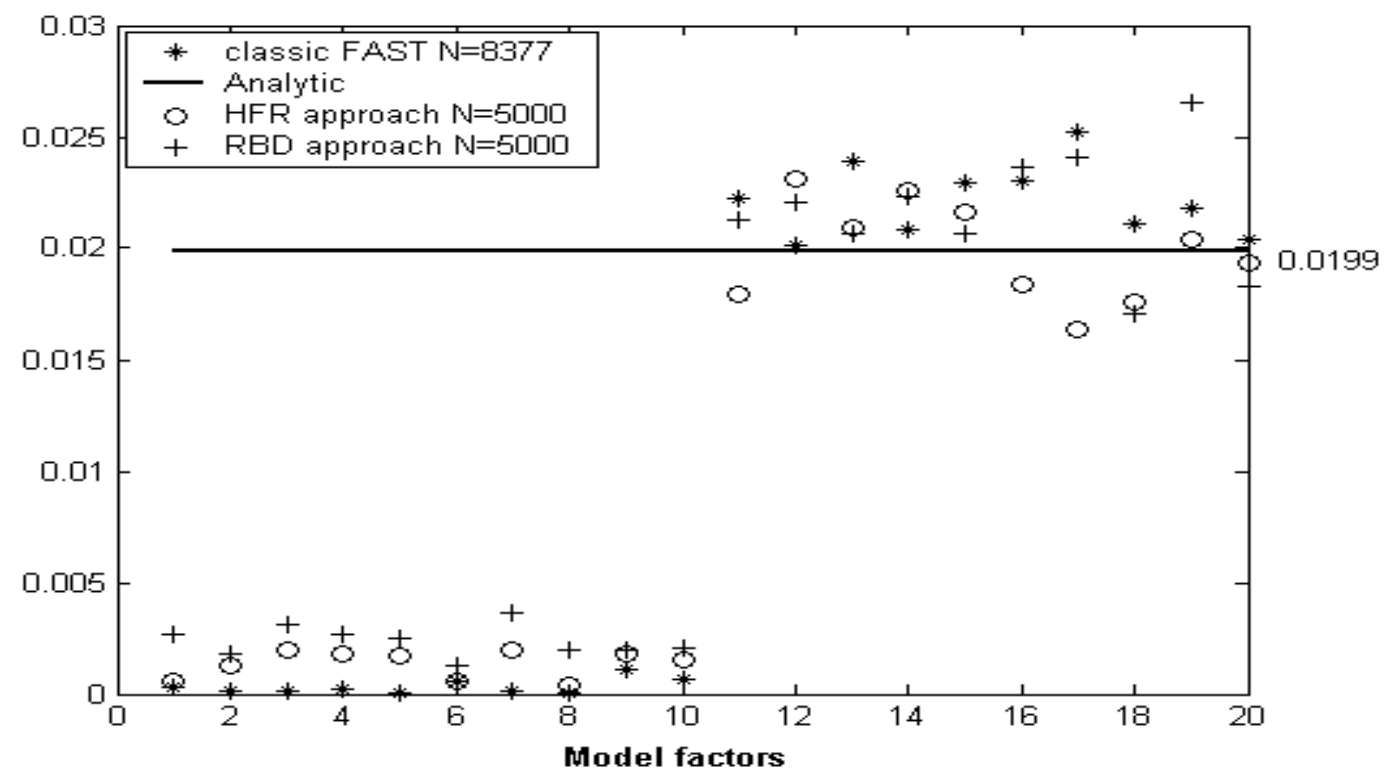

Figure 2 (a): First Test Case: G-function. The Estimated Values for the RBD approach, classic FAST and HFR, in a Case Study with a Large Number of Important Factors (10 very important and 10 non significant ones). $\mathrm{N}=5,000$ for the HFR and the RBD approaches, while $\mathrm{N}=8377$ for the Classic FAST. 


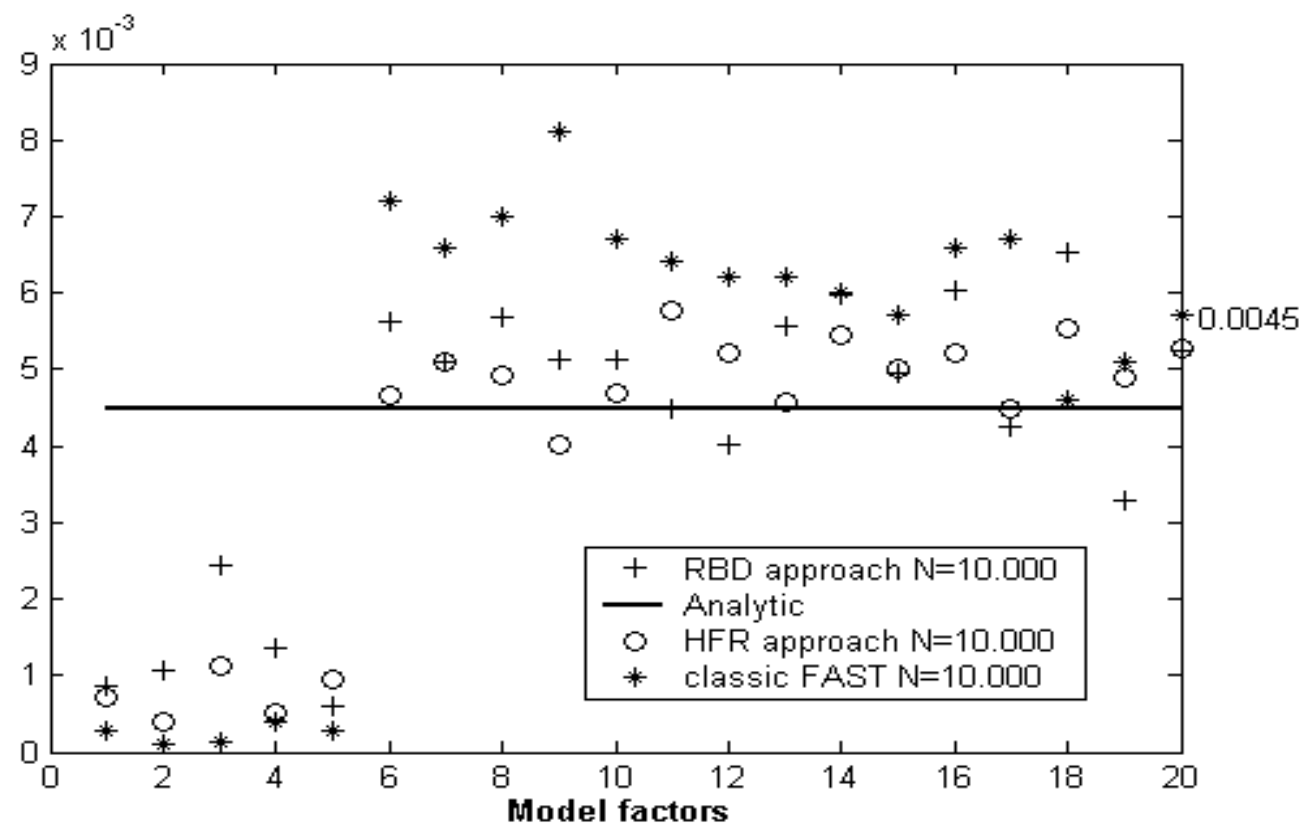

Figure 2 (b): First Test Case: G-function. The Estimated Values for the RBD approach, classic FAST and HFR, in a Case Study with a Large Number of Important Factors (15 very important and 5 non significant ones). $\mathrm{N}=10,000$.



Figure 3 (a): Second Test Case: Level-E. Comparison between the method of Saltelli (2002) and the RBD approach, for input factor 4. 


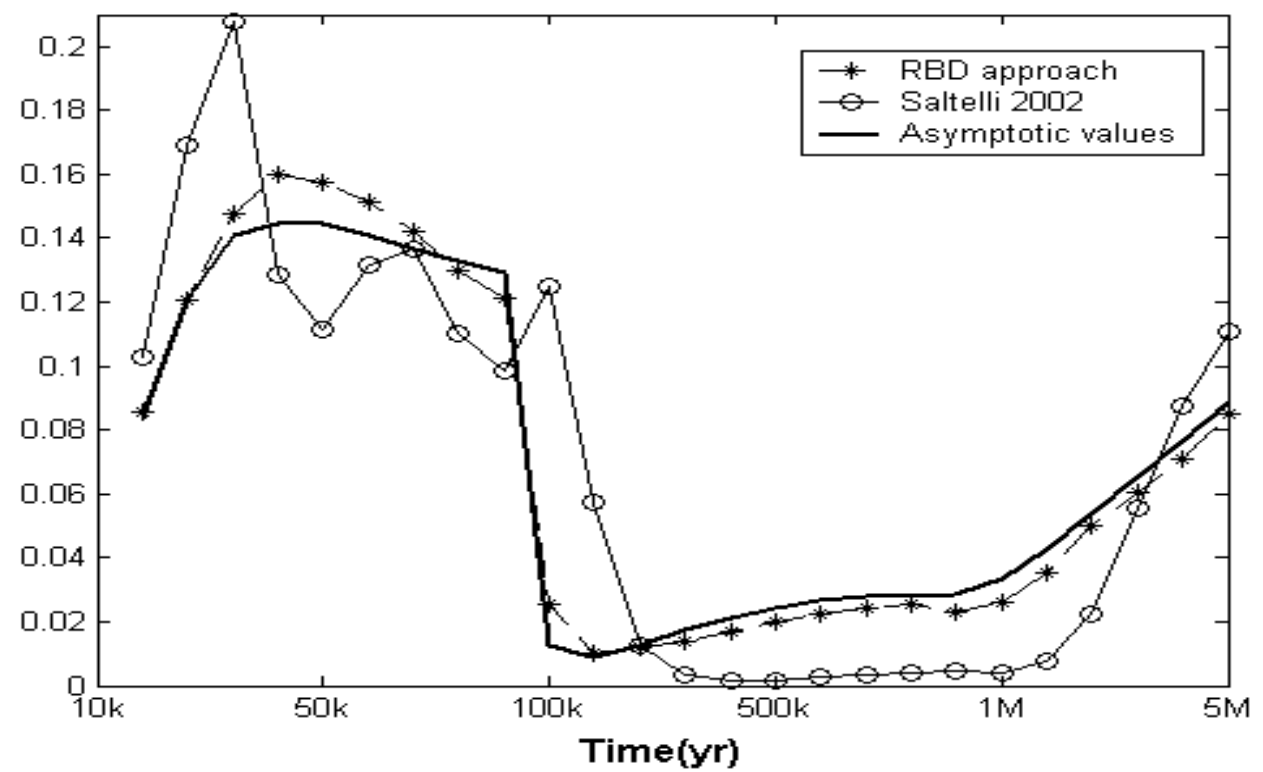

Figure 3 (b): Second Test Case: Level-E. Comparison between the method of Saltelli (2002) and the RBD approach, for input factor 12 .

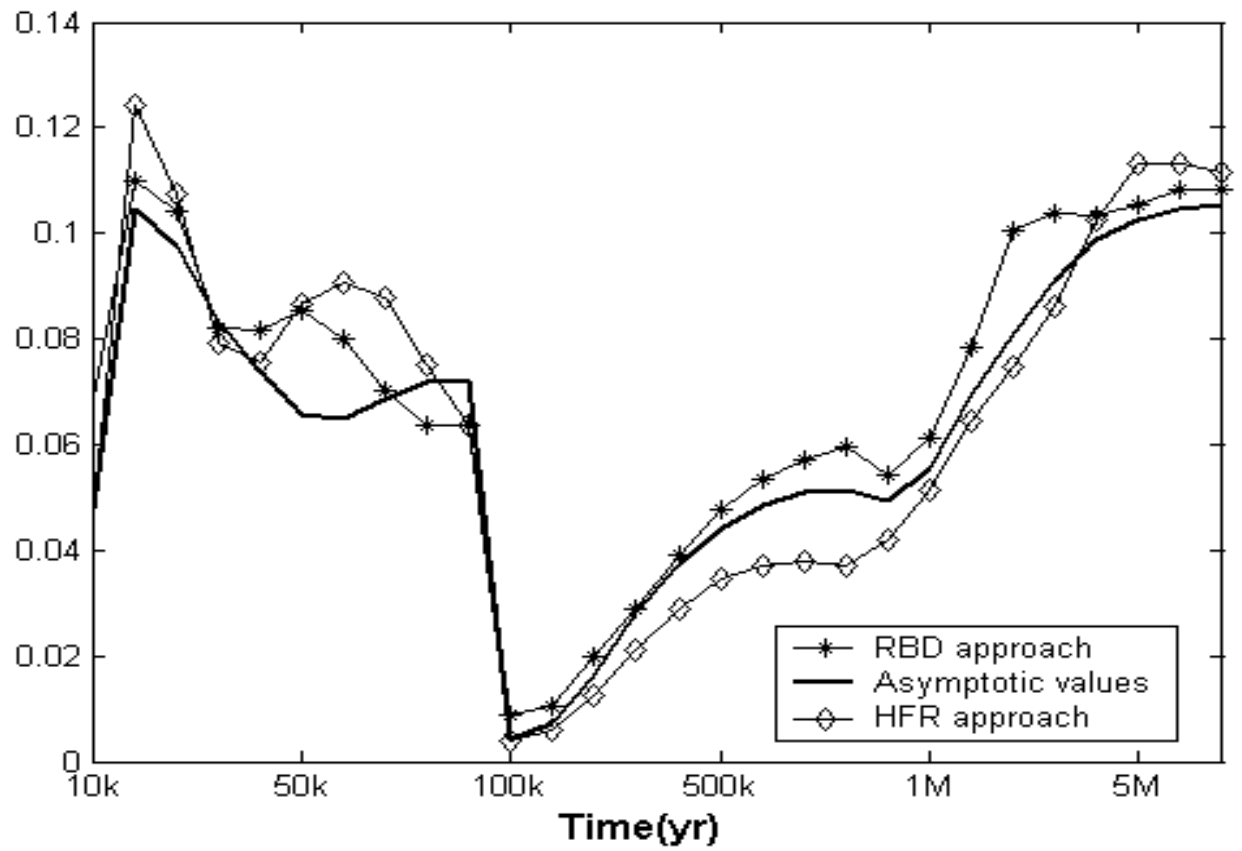

Figure 4 (a): Second Test Case: Level-E. Comparison between the RBD and the HFR approaches, for input factor 4 . 


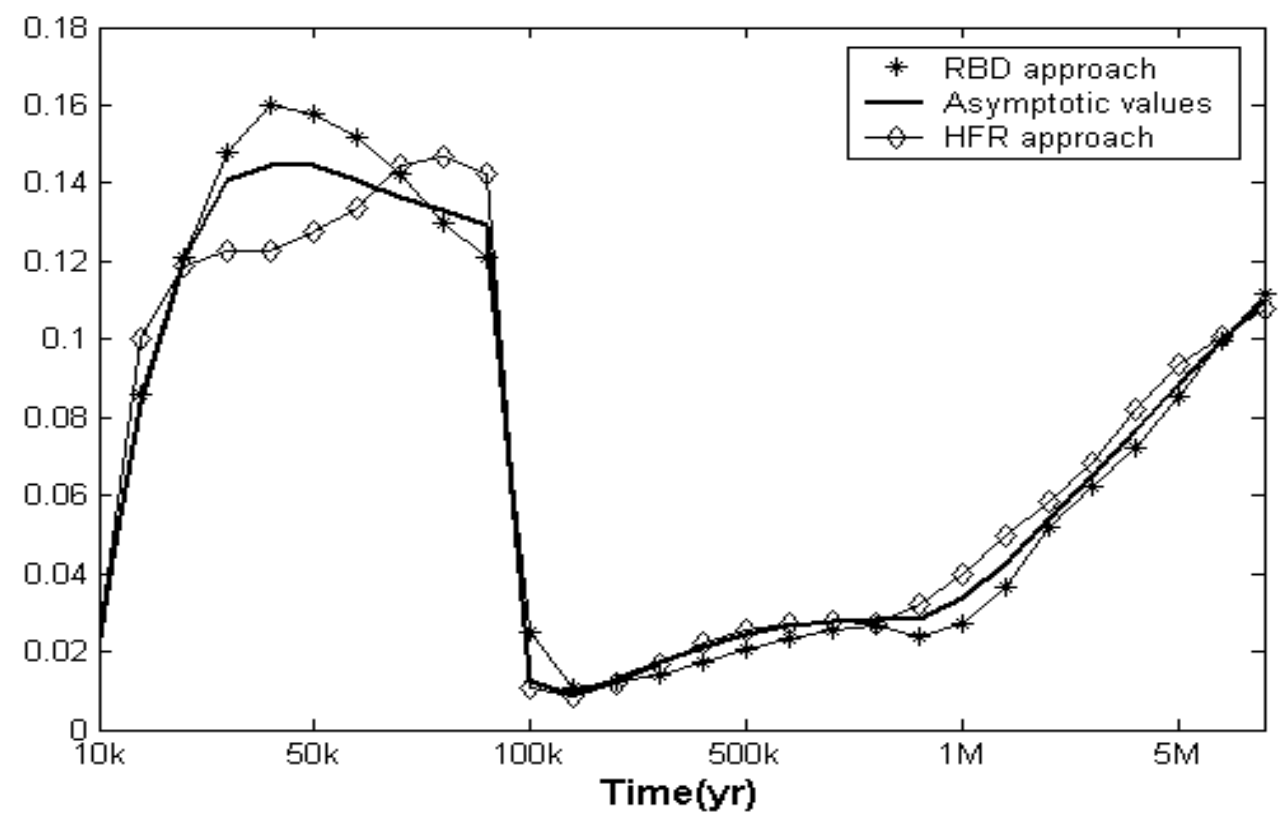

Figure 4 (b): Second Test Case: Level-E. Comparison between the RBD and the HFR approaches, for input factor 12 .

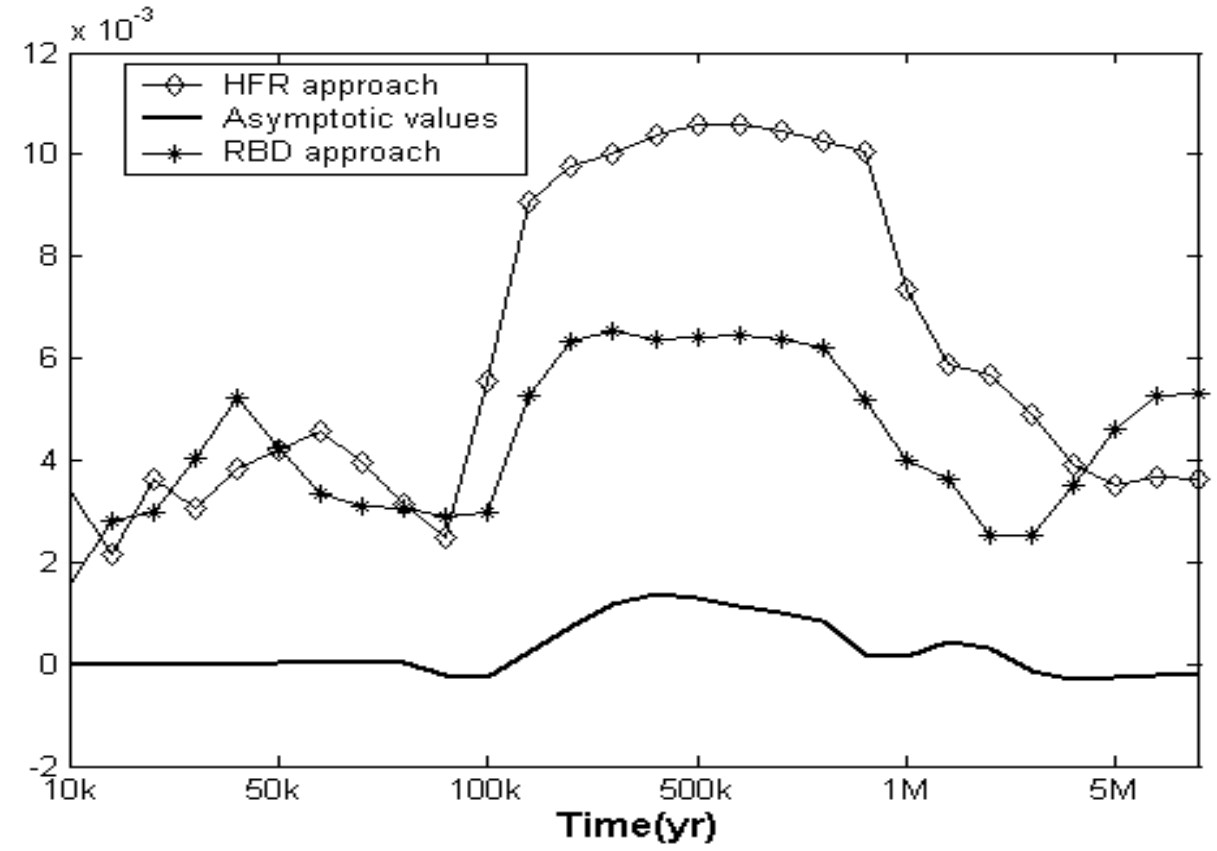

Figure 4 (c): Second Test Case: Level-E. Comparison between the RBD and the HFR approaches, for input factor 3 . 


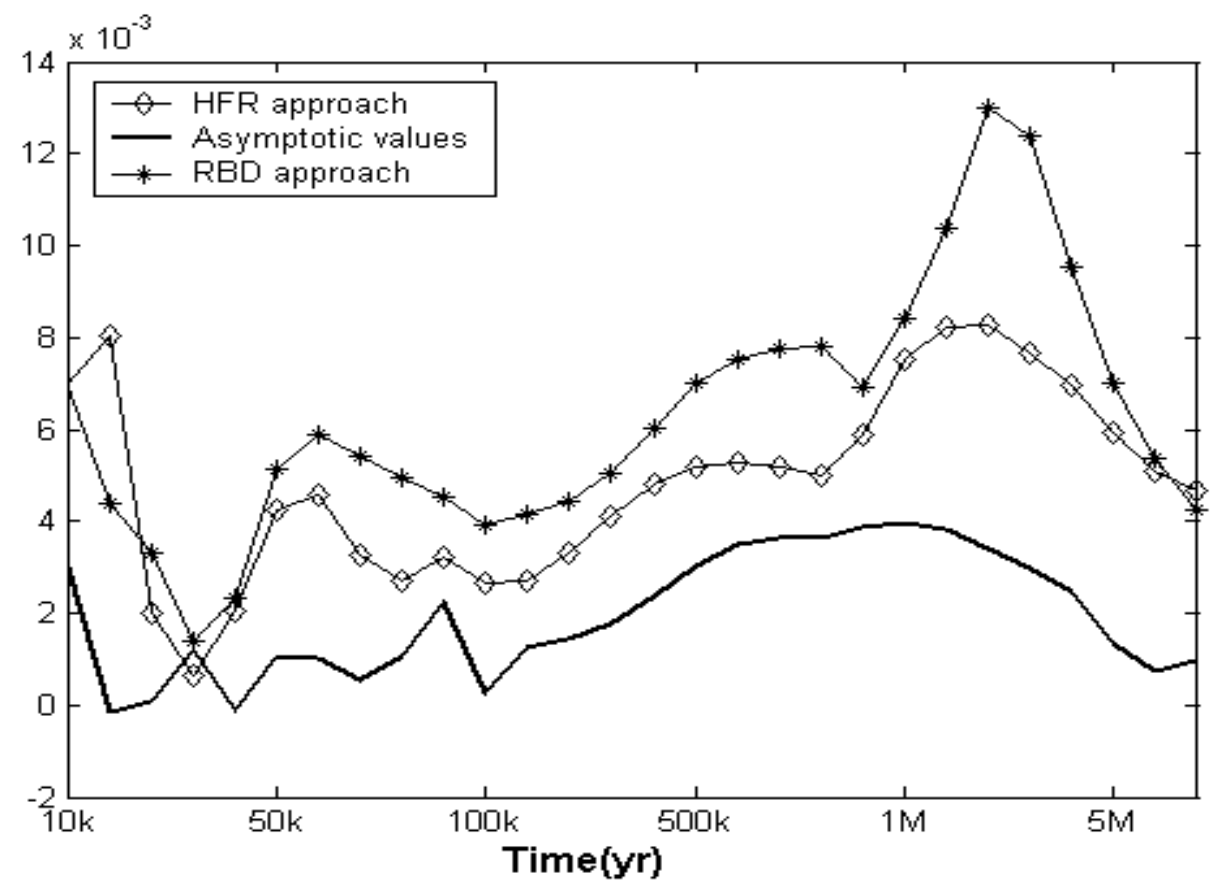

Figure 4 (d): Second Test Case: Level-E. Comparison between the RBD and the HFR approaches, for input factor 9 .
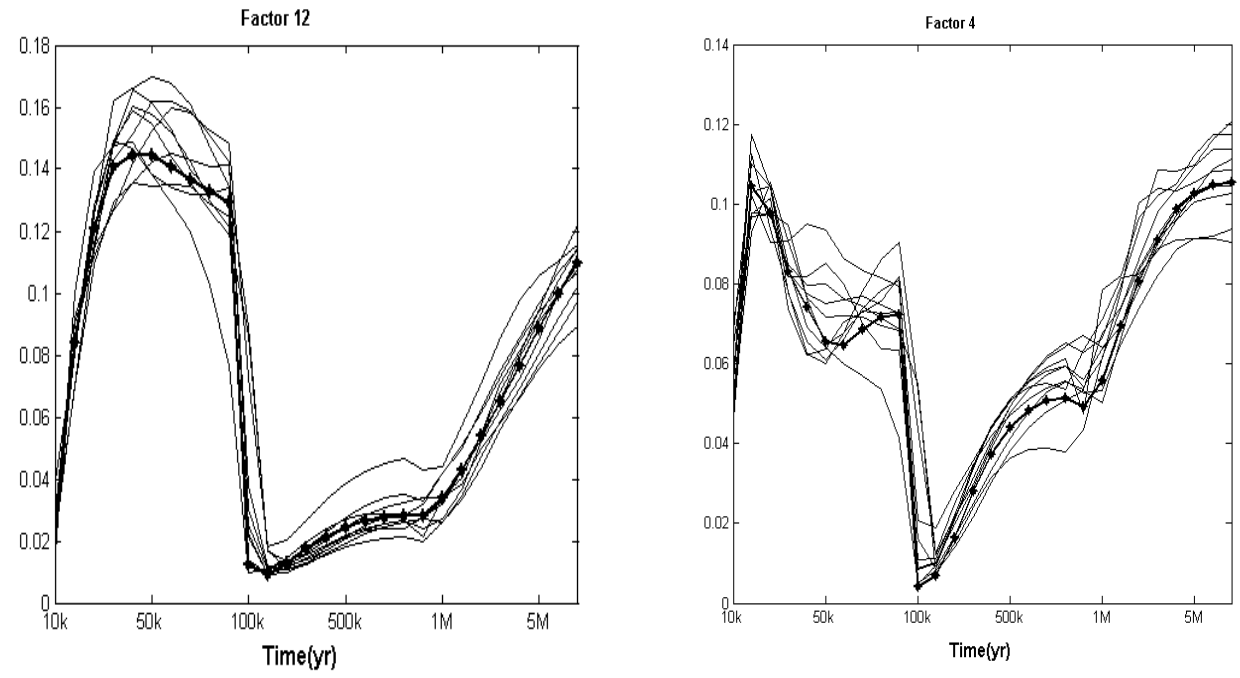

Figure 5 (a): Second Test Case: Level-E. Estimates widths for 10 experiments (on factor 12 and factor 4), in the RBD approach. 

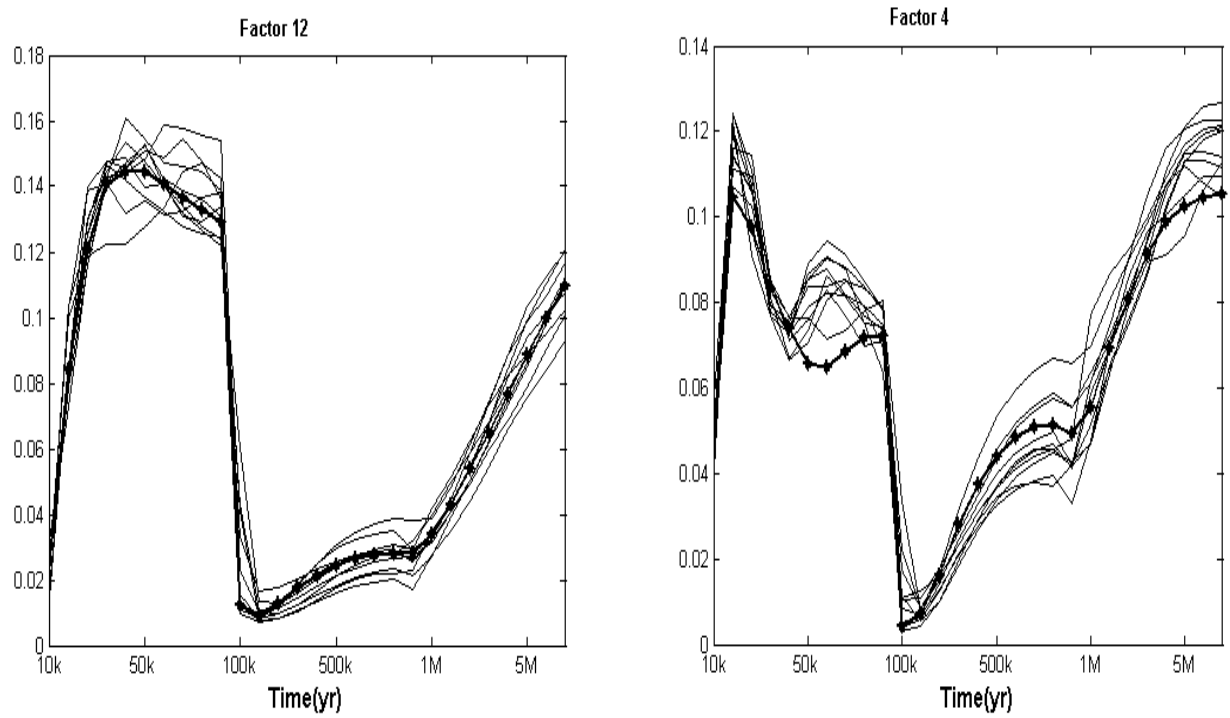

Figure 5 (b): Second Test Case: Level-E. Estimates widths for 10 experiments (for factor 12 and factor 4), in the HFR approach.

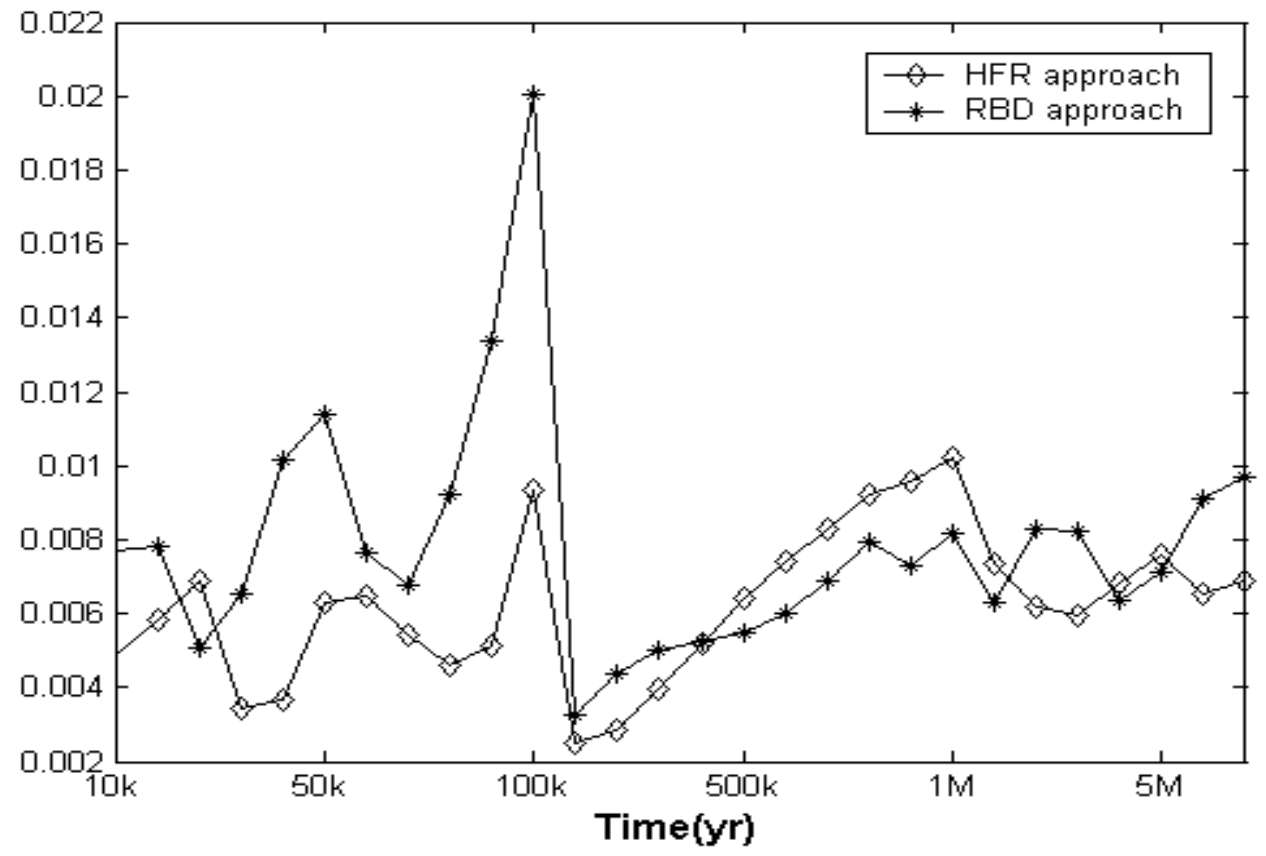

Figure 6 (a): Comparison between the standard deviation of 10 level-E experiments in the proposed methods (HFR and RBD) for factor 4. 


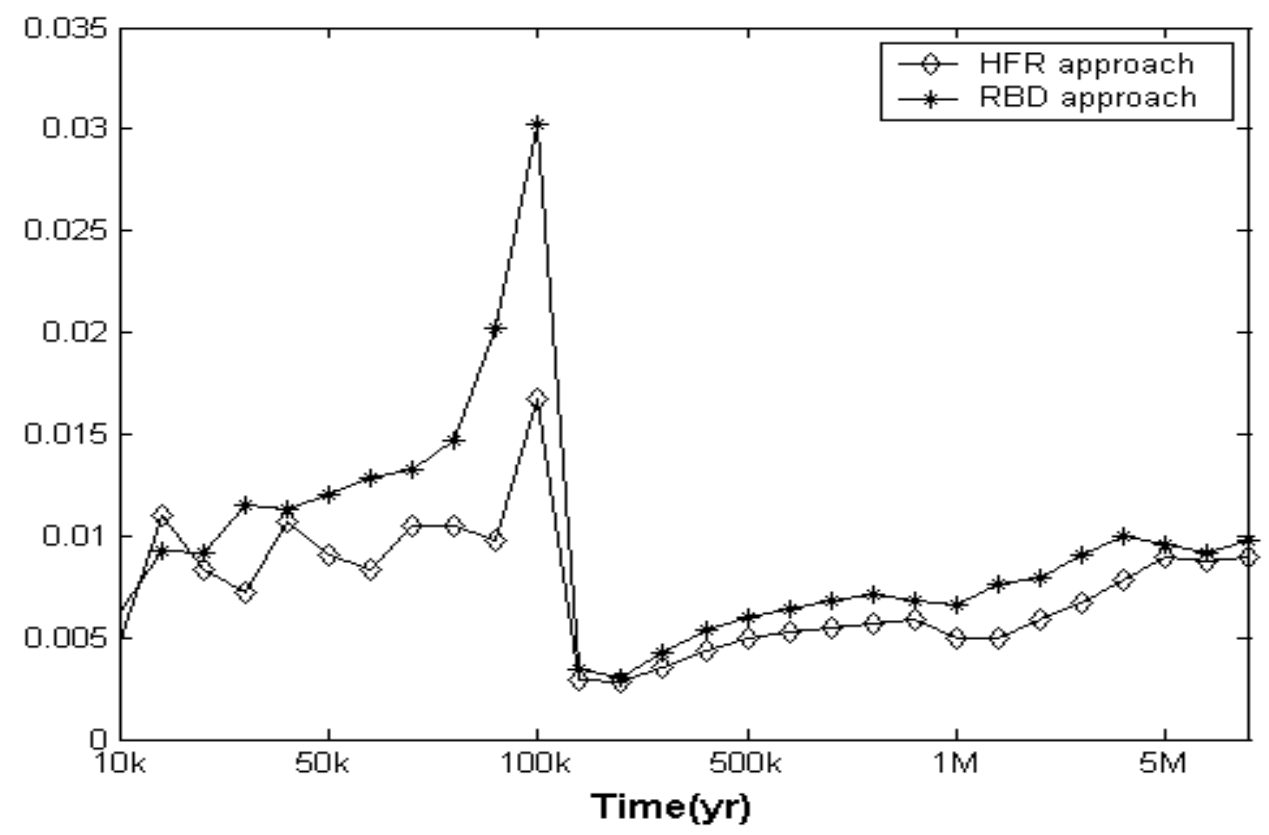

Figure 6 (b): Comparison between the standard deviation of 10 level-E experiments in the proposed methods (HFR and RBD) for factor 12.

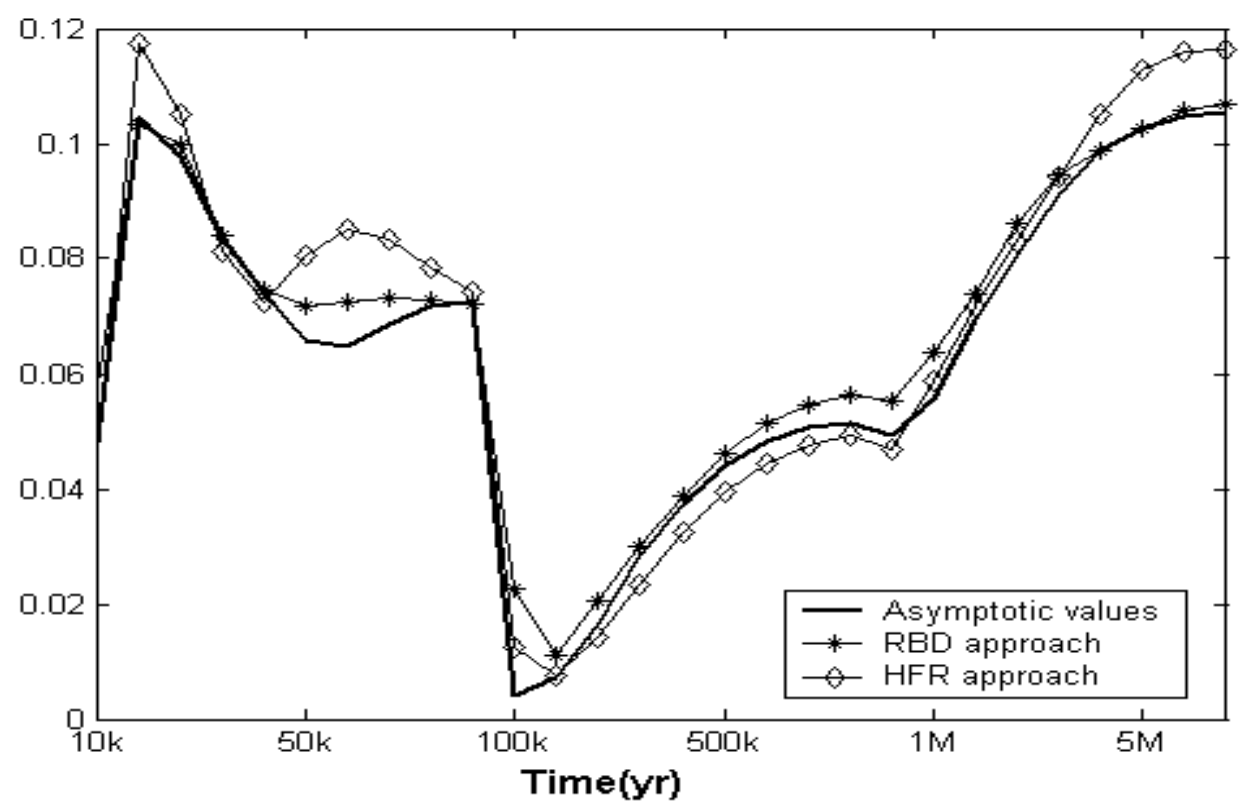

Figure 7 (a): Comparison between the means of 10 level-E experiments in the proposed methods (HFR and $\mathrm{RBD})$ for factor 4 . 


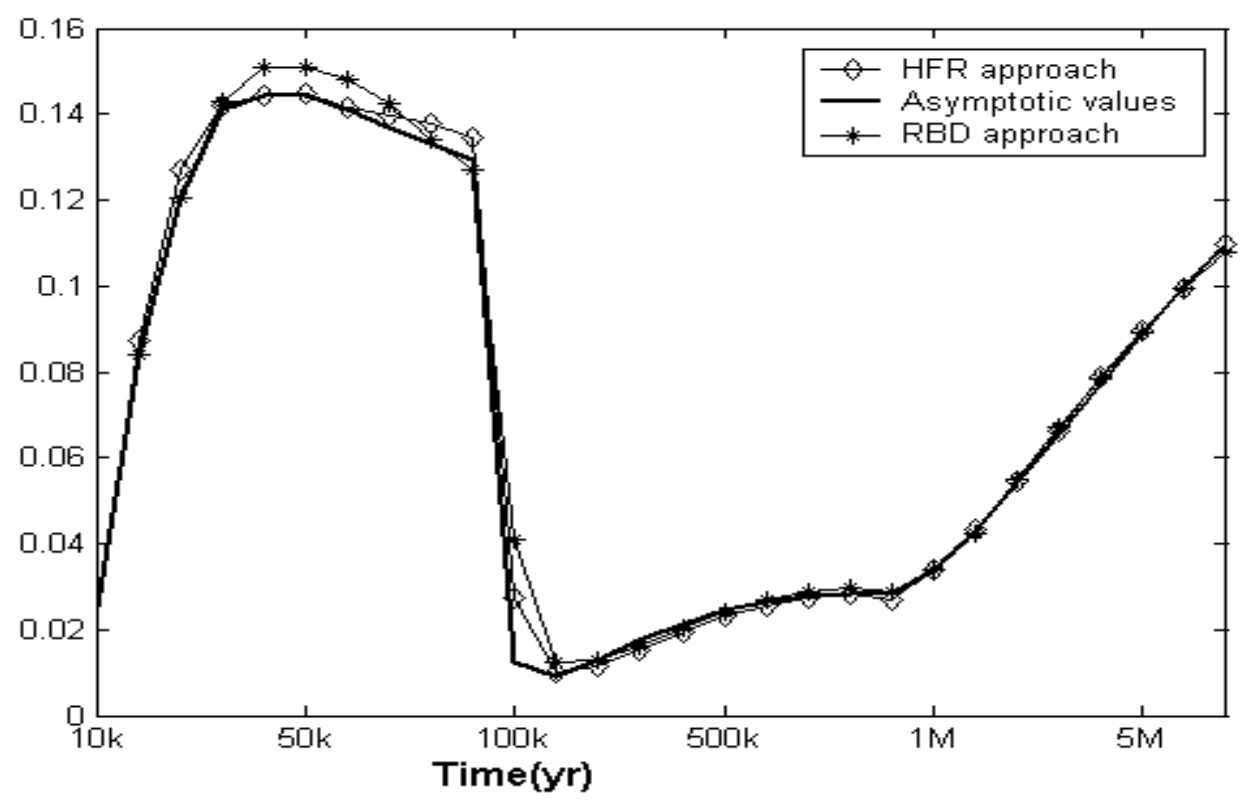

Figure 7 (b): Comparison between the means of 10 level-E experiments in the proposed methods (HFR and RBD) for factor 12 . 


\section{TABLES}

Table 1(a): G-function's Analytic Values and Estimates for First Orders in a Sample Size of N=1,000. The Estimates are Calculated both with the RBD and the Hybrid FAST-RBD Approach

\begin{tabular}{|l|c|c|c|}
\hline & Analytic values & The RBD approach & Hybrid FAST-RBD \\
\hline Factor 1 & 0.716 & 0.7200 & 0.6998 \\
\hline Factor 2 & 0.1790 & 0.1954 & 0.1873 \\
\hline Factor 3 & 0.024 & 0.0288 & 0.0247 \\
\hline Factor 4 & 0.0072 & 0.0210 & 0.0140 \\
\hline Factor 5 & $7.162 * 10^{-5}$ & 0.0125 & 0.0021 \\
\hline Factor 6 & $7.162 * 10^{-5}$ & 0.0119 & 0.0210 \\
\hline Factor 7 & $7.162 * 10^{-5}$ & 0.0103 & 0.0111 \\
\hline Factor 8 & $7.162 * 10^{-5}$ & 0.0108 & 0.0062 \\
\hline
\end{tabular}

Table 1(b): G-function's Analytic Values and Estimates for First Orders in a Sample Size of N=10,000. The Estimates are Calculated both with the RBD and the Hybrid FAST-RBD Approach

\begin{tabular}{|l|c|c|c|}
\hline & Analytic values & The RBD approach & Hybrid FAST-RBD \\
\hline Factor 1 & 0.716 & 0.7159 & 0.7091 \\
\hline Factor 2 & 0.1790 & 0.1790 & 0.1830 \\
\hline Factor 3 & 0.024 & 0.0250 & 0.0231 \\
\hline Factor 4 & 0.0072 & 0.0083 & 0.0096 \\
\hline Factor 5 & $7.162 * 10^{-5}$ & 0.0015 & 0.0002 \\
\hline Factor 6 & $7.162 * 10^{-5}$ & 0.0015 & 0.0011 \\
\hline Factor 7 & $7.162 * 10^{-5}$ & 0.0013 & 0.0006 \\
\hline Factor 8 & $7.162 * 10^{-5}$ & 0.0015 & 0.0008 \\
\hline
\end{tabular}


Table 2: Results of the two Proposed Methods Under Different Conditions. The Estimates are Calculated as the Mean of the Estimates Obtained in the 50 Repetitions of the Exercise. This has been done for three Different Sample Sizes

$\mathbf{N}=\mathbf{5 0 0}$, no. of experiments $=50$

\begin{tabular}{|c|c|c|c|c|c|}
\hline & Analytic values & \multicolumn{2}{|c|}{ The RBD approach } & \multicolumn{2}{c|}{ Hybrid FAST-RBD } \\
\hline & & Mean & $\begin{array}{c}\text { Standard } \\
\text { deviation }\end{array}$ & Mean & Standard deviation \\
\hline Factor 1 & 0.7160 & 0.7196 & 0.0173 & 0.7079 & 0.0136 \\
\hline Factor 2 & 0.1790 & 0.1986 & 0.0249 & 0.1833 & 0.0235 \\
\hline Factor 3 & 0.0240 & 0.0482 & 0.0189 & 0.0399 & 0.0144 \\
\hline Factor 4 & 0.0072 & 0.0318 & 0.0117 & 0.0223 & 0.0108 \\
\hline Factor 5 & 0.0001 & 0.0236 & 0.0083 & 0.0044 & 0.0022 \\
\hline Factor 6 & 0.0001 & 0.0237 & 0.0073 & 0.0122 & 0.0053 \\
\hline Factor 7 & 0.0001 & 0.0238 & 0.0107 & 0.0152 & 0.0071 \\
\hline Factor 8 & 0.0001 & 0.0253 & 0.0083 & 0.0188 & 0.0077 \\
\hline
\end{tabular}

$\mathbf{N}=\mathbf{1 0 0 0}$, no. of experiments $=50$

\begin{tabular}{|l|c|c|c|c|c|}
\hline & Analytic values & \multicolumn{2}{|c|}{ The RBD approach } & \multicolumn{2}{c|}{ Hybrid FAST-RBD } \\
\hline & & Mean & $\begin{array}{l}\text { Standard } \\
\text { deviation }\end{array}$ & Mean & Standard deviation \\
\hline Factor 1 & 0.7160 & 0.7168 & 0.0096 & 0.7073 & 0.0112 \\
\hline Factor 2 & 0.1790 & 0.1873 & 0.0167 & 0.1815 & 0.0207 \\
\hline Factor 3 & 0.0240 & 0.0348 & 0.0088 & 0.0311 & 0.0094 \\
\hline Factor 4 & 0.0072 & 0.0172 & 0.0064 & 0.0143 & 0.0058 \\
\hline Factor 5 & 0.0001 & 0.0110 & 0.0040 & 0.0021 & 0.0010 \\
\hline Factor 6 & 0.0001 & 0.0122 & 0.0044 & 0.0057 & 0.0028 \\
\hline Factor 7 & 0.0001 & 0.0128 & 0.0038 & 0.0069 & 0.0030 \\
\hline Factor 8 & 0.0001 & 0.0113 & 0.0046 & 0.0084 & 0.0043 \\
\hline
\end{tabular}

$\mathbf{N}=\mathbf{2 0 0 0}$, no. of experiments $=50$

\begin{tabular}{|c|c|c|c|c|c|}
\hline & \multirow[t]{2}{*}{ Analytic values } & \multicolumn{2}{|c|}{ The RBD approach } & \multicolumn{2}{|c|}{ Hybrid FAST-RBD } \\
\hline & & Mean & $\begin{array}{l}\text { Standard } \\
\text { deviation }\end{array}$ & Mean & Standard deviation \\
\hline Factor 1 & 0.7160 & 0.7171 & 0.0069 & 0.7057 & 0.0061 \\
\hline Factor 2 & 0.1790 & 0.1849 & 0.0133 & 0.1783 & 0.0147 \\
\hline Factor 3 & 0.0240 & 0.0304 & 0.0074 & 0.0277 & 0.0066 \\
\hline Factor 4 & 0.0072 & 0.0127 & 0.0046 & 0.0114 & 0.0045 \\
\hline Factor 5 & 0.0001 & 0.0062 & 0.0026 & 0.0012 & 0.0006 \\
\hline Factor 6 & 0.0001 & 0.0057 & 0.0024 & 0.0036 & 0.0017 \\
\hline Factor 7 & 0.0001 & 0.0058 & 0.0022 & 0.0043 & 0.0016 \\
\hline Factor 8 & 0.0001 & 0.0060 & 0.0027 & 0.0043 & 0.0025 \\
\hline
\end{tabular}


Table 3: Comparison between the estimates obtained with the three methods under analysis (Classic Fast, RBD, Hybrid FAST-RBD) in a case-study with 10 very important factors $\left(\mathrm{a}_{\mathrm{i}}=0\right)$ and 10 non significant factors $\left(\mathrm{a}_{\mathrm{i}}=99\right)$.

\begin{tabular}{|c|c|c|c|c|c|}
\hline & $\begin{array}{c}\text { Analytic } \\
\text { values }\end{array}$ & & $\begin{array}{l}\text { The RBD } \\
\text { approach }\end{array}$ & $\begin{array}{c}\text { Hybrid FAST- } \\
\text { RBD }\end{array}$ & Classic FAST \\
\hline \multirow{2}{*}{ Important factors } & \multirow{2}{*}{0.0199} & Mean & 0.0217 & 0.0198 & 0.0221 \\
\hline & & Variance & $1.1014 \mathrm{e}-005$ & $5.0911 \mathrm{e}-006$ & $8.2378 \mathrm{e}-006$ \\
\hline \multirow{2}{*}{$\begin{array}{c}\text { Non important } \\
\text { factors }\end{array}$} & \multirow{2}{*}{$1.988 \mathrm{e}-006$} & Mean & 0.0024 & 0.0014 & $3.2799 \mathrm{e}-004$ \\
\hline & & Variance & $6.7384 \mathrm{e}-006$ & $2.4595 \mathrm{e}-006$ & $2.3382 \mathrm{e}-007$ \\
\hline
\end{tabular}

Table 4: Comparison between the estimates obtained with the three methods under analysis (Classic FAST, RBD, Hybrid FAST-RBD) in a case-study with 15 very important factors $\left(\mathrm{a}_{\mathrm{i}}=0\right)$ and 5 non significant factors $\left(\mathrm{a}_{\mathrm{i}}=99\right)$.

\begin{tabular}{|c|c|c|c|c|c|}
\hline & $\begin{array}{c}\text { Analytic } \\
\text { values }\end{array}$ & & $\begin{array}{c}\text { The RBD } \\
\text { approach }\end{array}$ & $\begin{array}{c}\text { Hybrid FAST- } \\
\text { RBD }\end{array}$ & Classic FAST \\
\hline \multirow{2}{*}{ Important factors } & 0.0045 & Mean & 0.0086 & 0.0047 & 0.0063 \\
\cline { 3 - 6 } & Variance & $3.1128 \mathrm{e}-006$ & $1.2586 \mathrm{e}-006$ & $7.2886 \mathrm{e}-007$ \\
\hline $\begin{array}{c}\text { Non important } \\
\text { factors }\end{array}$ & $4.514 \mathrm{e}-007$ & Mean & 0.0025 & $6.4000 \mathrm{e}-004$ & $2.3720 \mathrm{e}-004$ \\
\cline { 3 - 6 } & & Variance & $3.9133 \mathrm{e}-007$ & $2.8000 \mathrm{e}-0008$ & $1.2315 \mathrm{e}-008$ \\
\hline
\end{tabular}

Table 5: Description of the Input Parameters and their Probability Distributions for the Level-E Exercise

\begin{tabular}{|c|c|c|c|c|}
\hline Notation & Definition & Distribution & Range & Units \\
\hline $\mathbf{T}$ & Containment time & Uniform & $/ 100,1000 /$ & $\mathrm{yr}$ \\
\hline $\mathbf{k}_{\mathrm{I}}$ & Leach rate for iodine & Log-uniform & $/ 10^{-3}, 10^{-2} /$ & $\mathrm{yr}^{-1}$ \\
\hline $\mathbf{k}_{\mathrm{C}}$ & Leach rate for $\mathrm{Np}$ chain nuclides & Log-uniform & $/ 10^{-6}, 10^{-5} /$ & $\mathrm{yr}^{-1}$ \\
\hline $\mathbf{v}^{(1)}$ & Water vel. In geosphere's $1^{\text {st }}$ layer & Log-uniform & $/ 10^{-3}, 10^{-1} /$ & $\mathrm{m} / \mathrm{yr}$ \\
\hline $\mathbf{l}^{(1)}$ & Length of geosphere's $1^{\text {st }}$ layer & Uniform & $/ 100,500 /$ & $\mathrm{m}$ \\
\hline$\overline{\mathbf{R}_{\mathrm{I}}^{(1)}}$ & Retention factor for I ( $1^{\text {st }}$ layer $)$ & Uniform & $/ 1,5 /$ & - \\
\hline $\mathbf{R}_{\mathbf{C}}{ }^{(1)}$ & Factor to compute ret. coeff. For $\mathrm{Np}\left(1^{\text {st }}\right.$ layer $)$ & Uniform & $/ 3,30 /$ & - \\
\hline $\mathbf{v}^{(2)}$ & Water vel. In geosphere's $2^{\text {nd }}$ layer & Log-uniform & $/ 10^{-2}, 10^{-1} /$ & $\mathrm{m} / \mathrm{yr}$ \\
\hline $\mathbf{1}^{(2)}$ & Length of geosphere's $2^{\text {nd }}$ layer & Uniform & $/ 50,20 /$ & $\mathrm{m}$ \\
\hline$\overline{\mathbf{R}_{\mathrm{I}}^{(2)}}$ & Retention factor for I ( $2^{\text {nd }}$ layer $)$ & Uniform & $/ 1,5 /$ & - \\
\hline $\mathbf{R}_{\mathbf{C}}^{(2)}$ & Factor to compute ret. coeff. For $\mathrm{Np}\left(2^{\text {nd }}\right.$ layer $)$ & Uniform & $/ 3,30 /$ & - \\
\hline $\mathbf{W}$ & Stream flow rate & Log-uniform & $/ 10^{5}, 10^{7} /$ & $\mathrm{m}^{3} / \mathrm{yr}$ \\
\hline
\end{tabular}

